\title{
Contextual Associations of Interregional Income Gap with Physical Constitution and Dietary Environment in Individual Housebound Elderly
}

\author{
Fumie Okada $^{1,2}$, Takehiko Kaneko ${ }^{1}$, Satoshi Toyokawa ${ }^{3}$ \& Tadashi Furuhata ${ }^{1}$ \\ ${ }^{1}$ Department of Health and Nutrition, Wayo Women's University, Chiba, Japan \\ ${ }^{2}$ Koyo Nursing Nutrition College, Ibaraki, Japan \\ ${ }^{3}$ Graduate School of Medicine, The University of Tokyo, Tokyo, Japan \\ Correspondence: Satoshi Toyokawa, Graduate School of Medicine, The University of Tokyo, 7-3-1 Hongo, \\ Bunkyo, Tokyo, 113-0033, Japan. Tel: +81-3-5841-3494. E-mail: t-satoshi@umin.ac.jp
}

Received: January 25, 2020 Accepted: March 6, 2020 Online Published: March 19, 2020

doi:10.5539/gjhs.v12n4p94 URL: https://doi.org/10.5539/gjhs.v12n4p94

\begin{abstract}
Background: Much attention has been directed towards the issue of health inequalities associated with Japan's widening income gap. Focusing on the housebound elderly, we assessed the contextual associations of the interregional income gap with body mass index (BMI).

Method: A total of 15,200 housebound elderly living in 46 of the country's 47 prefectures, except for Tokyo, were interviewed face-to-face using a questionnaire that covered age, gender, height, weight, medical history, utilization of nursing care, family, source of income, food consumption, and physical activity. To determine the relationship between BMI and the above-mentioned items, a linear regression analysis was performed. In the multilevel analysis, we assumed a prefecture-level random intercept on the basis of the data on the average income per capita in the 46 prefectures.
\end{abstract}

Results: Valid responses without missing data were obtained from 10,226 respondents (response rate: 67.3\%) and used for the analyses; females accounted for $78.5 \%(\mathrm{n}=8,027)$ of the sample. In the multilevel analysis, prefectural average income showed a significant contextual negative association with BMI in females $(-0.846 ; P=0.001)$.

Conclusions: Prefectural average income has a significant negative contextual association with individual-level BMI for females; females with a low rate of going out have lower BMI; and females living with children have higher BMI. Social environment may be correlated with BMI in the older population.

Keywords: elderly, income gap, BMI, eating habits, contextual associations, state level, neighbourhood

\section{List of Abbreviations}

BMI: Body Mass Index

\section{Background}

Recently, in Japan, much attention has been focused on the issue of health inequalities associated with the widening income gap (Imai, 2007). Health inequalities are the differences in people's health caused by variations in social status represented by race, education, occupation, and income (Berkman \& Kawachi, 2000; Wilkinson \& Marmot, 2003). Kawachi , Fujisawa, and Takano (2007) suggested that a state or metropolitan-level income gap in the United States has an adverse effect on health (Kawachi, Fujisawa, \& Takano, 2007). The overall risks of death, cancer, and poor self-rated health are related to low socioeconomic status even in the elderly (Fujino et al., 2005; Ichida et al, 2009; Kondo et al., 2009; Murata Kondo, Hirai, Ichida, \& Ojima, 2008). The income gap in Japan is currently widening because of the rise in the proportion of the elderly in the population and the increase in the rate of one-person households (Fukuda \& Imai, 2007), which may result in the deterioration of the health of the elderly.

One of the urgent health issues in this so-called superaged society is malnutrition at various levels (Takemi \& Koiwai, 2017). It has been reported that the elderly tend to require long-term care and that their risk of death increases because of persistent malnutrition (Takemi \& Koiwai, 2017). A previous study in Japan showed that the elderly, regardless of whether they reside in care facilities or their own homes, are likely to be malnourished; 30 
$40 \%$ of the elderly had a serum albumin level of $3.5 \mathrm{~g} / \mathrm{dl}$ or lower (Sugiyama, 2005). Serum albumin levels were lower in Japanese elderly with low economic status (Ota et al., 2013). The decrease in albumin levels appears to be mediated by nutrition and health-related factors in conjunction with low household income (Ota et al., 2013).

Obesity, a significant health issue across age groups (Examination Committee of Criteria for Obesity Disease in Japan, 2011), is a risk factor for glucose intolerance, arteriosclerotic disease, and hypertension, and leads to the deterioration of activities of daily living, which results in an increase in medical costs (Cabinet Office, Japan, 2014). In a worldwide study (Global BMI Mortality Collaboration, 2016), all-cause mortality was minimal at a body mass index (BMI) of $20.0-25.0 \mathrm{~kg} / \mathrm{m}^{2}$ and increased significantly just below this range (BMI 18.5-<20.0 $\mathrm{kg} / \mathrm{m}^{2} ; 1.13$ ). While all-cause mortality in the overweight range (BMI $25.0-<27.5 \mathrm{~kg} / \mathrm{m}^{2} ; 1.07$ ) was also significantly high, its effect was small. A distinct increase in mortality was seen for obesity grade 1 (BMI 30.0 $<35.0$; 1.45) (Global BMI Mortality Collaboration, 2016).

Focusing on the older population, obesity may be a protective factor for all-cause mortality rate compared with thinness or normal weight in older community-dwelling Americans (Grabowski \& Ellis, 2001). Even in the Japanese context, a recent survey revealed that in the elderly, low BMI was associated with increased risk of all-cause mortality, even among those in the lower normal BMI range (Tamakoshi et al., 2010). Another study reported that in the older population, obesity (BMI $\geq 30$ ) is associated with frailty (Blaum, Xue, Michelon, Semba, \& Fried, 2005); however, there are few individuals of obesity grade 1 in the Japanese older population. BMI is one of the factors used to calculate the Geriatric Nutritional Risk Index (Kunimura et al., 2017), and along with serum albumin level, is often used as an indicator of nutritional status in routine clinical practice (Haass et al., 2011; Kenchaiah et al., 2007). Since the older population already has a high prevalence of noncommunicable diseases such as arteriosclerotic disease and hypertension, obesity is not an indicator of noncommunicable diseases or, more importantly, physical constitution, malnutrition, and frailty.

Focusing on the housebound elderly, in this study, we assessed the contextual associations of the interregional income gap with BMI as an index of malnutrition and frailty.

\section{Methods}

\subsection{Target and Survey Method}

The participants of this survey were 15,200 older adults aged 65 years or above living at home in 46 prefectures (excluding Tokyo) as of November 1, 2012. A questionnaire titled the 'Survey on Dietary Environment in Relation to Difficulty in Shopping and Current Health Conditions of Household Elderly' was randomly distributed to older adults living at home near the trained investigators (Okada, Toyokawa, Kaneko, \& Furuata et al., 2012; Okada, Toyokawa, Kaneko, \& Furuata et al., 2020),. A total of 12,782 surveys were collected and data of 10,226 participants were analysed (analysis rate: $67.3 \%$ ).

The questionnaire included 31 question items regarding age, gender, height, weight, family composition, locomotive syndrome, hypertension, diabetes, history of heart disease, dental health, food procurement methods, dietary content, frequency of outings, subjective health, and the use of public services such as long-term care insurance and meal delivery services. The analysis set comprised responses of 2,199 males and 8,027 females who completed all of the 13 question items that were analysed.

BMI was classified into three categories: underweight (20 or less), normal (more than 20 and less than 25), and obese (25 or more) according to Health Japan 21's (second term) criteria for older adults (Takemi \& Koiwai, 2017). Family composition was classified into three categories: 'one-person households', 'married households' and 'the subject and their child(ren) or others'. The main sources of income for living expenses were classified into two categories: 'pension' and 'non-pension'. The need for nursing care was classified into three categories: 'needs support', 'needs nursing care' and 'uses neither'. Illnesses under treatment were classified under multiple responses, and 'locomotive syndrome (bone and joint diseases)' was classified into 'treated' and 'untreated. Those who answered "yes" to the question of whether they had diseases of the bones or joints that were being treated were determined to have locomotive syndrome. Dental condition was classified into two categories: "no difficulty biting' and 'difficulty biting', and the number of meals per day was classified into two categories: 'three or more meals' and 'two or fewer meals'. The contents of their meals were classified into two categories, 'yes' and 'no', according to whether they ate meat, fish, eggs, and soy products (tofu, natto, etc.) every day and whether they consumed milk and dairy products every day. The frequency of outings was classified into two categories: 'three or more times a week' and 'twice a week or less', and subjective health was classified into two categories: 'good or pretty good' and 'normal, not so good, or bad'. Income was obtained from the average per capita income of the 46 prefectures based on the 2011 report of the Cabinet Office's Economic and Social Research Institute (Cabinet 
Office, Japan, 2011). The use of average income as a community-level covariate has been recommended for investigating the association between income inequality and health (Blakely \& Kawachi, 2001).

\subsection{Statistical Analysis}

Mean values and standard deviation (SD) are shown by gender for age, height, weight, and BMI, and frequency and $\%$ are shown for categorical items. When comparing males and females, Welch's or Student's t-test was performed according to the variance of the two groups, and the $\chi 2$ test was used for the difference in frequency. A linear regression analysis was performed to examine the relationship between BMI and prefectural average income. Since income in our data is derived from aggregate measures for each prefecture, all subjects in the same prefecture have the same value, so we performed a prefecture-level random intercept, assuming random intercepts for each prefecture. Independent variables at the individual-level include age, household composition, income source, presence or absence of locomotive syndrome, dental health, consumption of milk and dairy, consumption of foods high in protein, subjective health, frequency of outings, and their necessary degree of care. Associations and differences were considered statistically significant when the $p$ value was $<.05$. Stata 13 (StataCorp, 2013) was used for analysis and MLwiN3.0 (University of Bristol, 2016) was used for multilevel analysis.

\subsection{Ethical Considerations}

This study was conducted in accordance with the ethical guidelines for epidemiological research of the Japanese Ministry of Education, Culture, Sports, Science and Technology and the guidelines of the Ministry of Health, Labour and Welfare. Research commenced after subjects were given a complete explanation of the study's goal from an investigator and provided consent. The survey and analysis were conducted with the approval of the Ethics Committee of Tokiwa University and Tokiwa Junior College (No. 100025).

\section{Results}

Valid responses without missing data were obtained from 10,226 respondents (response rate: $67.3 \%$ ) and used for the analyses; females accounted for $78.5 \%(\mathrm{n}=8,027)$ of the sample. Regarding the age distribution, those aged $65-$ 74 years accounted for $44.7 \%(n=4,576)$ and the mean age was 76.0 years (SD: 7.0). Table 1 shows the gender distribution of the sample.

Table 1. Attributes and health conditions of subjects

\begin{tabular}{|c|c|c|c|c|c|}
\hline & \multicolumn{2}{|l|}{ Males } & \multicolumn{2}{|c|}{ Females } & $P$-value \\
\hline & \multicolumn{2}{|l|}{2,199} & \multicolumn{2}{|l|}{8,027} & \\
\hline \multicolumn{6}{|l|}{ INDIVIDUAL LEVEL } \\
\hline Age (years) & \multicolumn{2}{|c|}{$75.8 \pm 7.0$} & \multicolumn{2}{|c|}{$76.0 \pm 7.0$} & 0.241 \\
\hline BMI $\left(\mathrm{kg} / \mathrm{m}^{2}\right)$ & \multicolumn{2}{|c|}{$22.8 \pm 2.7$} & \multicolumn{2}{|c|}{$22.5 \pm 3.1$} & $<0.001$ \\
\hline$<=20$ & \multicolumn{2}{|c|}{$300 \quad 13.6 \%$} & \multicolumn{2}{|c|}{$1,66120.7 \%$} & $<0.001$ \\
\hline$>20,<25$ & \multicolumn{2}{|c|}{$1,46966.8 \%$} & \multicolumn{2}{|c|}{$4,87160.7 \%$} & \\
\hline$>=25$ & \multicolumn{2}{|c|}{$430 \quad 19.6 \%$} & \multicolumn{2}{|c|}{$1,49518.6 \%$} & \\
\hline \multicolumn{6}{|l|}{ Household } \\
\hline Living with children, and others & \multicolumn{2}{|c|}{$421 \quad 19.1 \%$} & \multicolumn{2}{|c|}{$2,03725.4 \%$} & $<0.001$ \\
\hline One-person household & \multicolumn{2}{|c|}{$1,18353.8 \%$} & \multicolumn{2}{|c|}{$2,62932.8 \%$} & \\
\hline Married-couple household & \multicolumn{2}{|c|}{$595 \quad 27.1 \%$} & \multicolumn{2}{|c|}{$2,36129.4 \%$} & \\
\hline \multicolumn{6}{|l|}{ Major source of income } \\
\hline Other than a pension & \multicolumn{2}{|c|}{$246 \quad 11.2 \%$} & \multicolumn{2}{|c|}{$778 \quad 9.7 \%$} & 0.039 \\
\hline Pension & \multicolumn{2}{|c|}{$1,95388.8 \%$} & \multicolumn{2}{|c|}{$7,24990.3 \%$} & \\
\hline \multicolumn{6}{|c|}{ Use of na 甘onal $n$ ursing-care $i$ nsurance services } \\
\hline Support required & 111 & $5.0 \%$ & 573 & $7.1 \%$ & \\
\hline Need of nursing care & 109 & $5.0 \%$ & 307 & $3.8 \%$ & $<0.001$ \\
\hline No use & 1,979 & $90.0 \%$ & 7,147 & $89.0 \%$ & \\
\hline
\end{tabular}




\begin{tabular}{|c|c|c|c|c|c|}
\hline \multicolumn{6}{|l|}{ Self-rated health } \\
\hline Good and rather good & 1,040 & $47.3 \%$ & 3,762 & $46.9 \%$ & 0.722 \\
\hline Poor, and neither good nor poor & 1,159 & $52.7 \%$ & 4,265 & $53.1 \%$ & \\
\hline \multicolumn{6}{|l|}{ State of the tooth } \\
\hline Good & 1,321 & $60.1 \%$ & 5,047 & $62.9 \%$ & 0.016 \\
\hline It is hard to chew & 878 & $39.9 \%$ & 2,980 & $37.1 \%$ & \\
\hline \multicolumn{6}{|l|}{ Diseases under treatment } \\
\hline Locomotive syndrome, yes & 322 & $14.6 \%$ & 2,098 & $26.1 \%$ & $<0.001$ \\
\hline \multicolumn{6}{|l|}{ Daily consumption } \\
\hline Meat, fish, eggs, and soy products,yes & 2,087 & $94.9 \%$ & 7,756 & $96.6 \%$ & $<0.001$ \\
\hline Meat, fish, eggs, and soy products, no & 112 & $5.1 \%$ & 271 & $3.4 \%$ & \\
\hline Milk and dairy products, yes & 1,485 & $67.5 \%$ & 6,002 & $74.8 \%$ & $<0.001$ \\
\hline Milk and dairy products, no & 714 & $32.5 \%$ & 2,025 & $25.2 \%$ & \\
\hline \multicolumn{6}{|l|}{ Meal frequency per day } \\
\hline More than three meals & 2,085 & $94.8 \%$ & 7,732 & $96.3 \%$ & 0.001 \\
\hline Two meals or less & 114 & $5.2 \%$ & 295 & $3.7 \%$ & \\
\hline \multicolumn{6}{|l|}{ Frequency of going out } \\
\hline More than three times a week & 1,292 & $58.8 \%$ & 4,593 & $57.2 \%$ & 0.197 \\
\hline It is as follows twice a week & 907 & $41.2 \%$ & 3,434 & $42.8 \%$ & \\
\hline \multicolumn{6}{|l|}{ PREFECTURAL LEVEL } \\
\hline Prefecture average income ( 1 thousand yen) & \multicolumn{2}{|c|}{$2633.2 \pm 265.5$} & \multicolumn{2}{|c|}{$2634.5 \pm 260.9$} & 0.838 \\
\hline
\end{tabular}

Multilevel random intercept regression models for males showed significant association of BMI with age (-0.044, $P<0.001)$, two meals or less $(0.612 ; P=0.020)$, difficulty in chewing $(-0.241 ; P=0.048)$, requirement of support $(-0.779 ; P=0.004)$, and need of nursing care $(-0.847 ; P=0.002)$. Prefectural average income $(-0.312 ; P=0.227)$ was not significantly associated with BMI.

Multilevel random intercept regression models for females showed a significant association of BMI with age $(-0.055 ; P<0.001)$, one-person household $(-0.394 ; P=0.031)$, married-couple household $(-0.539 ; P=0.002)$, locomotive syndrome $(0.403 ; P<0.001)$, daily consumption of meat, fish, eggs, and soy products $(0.430 ; 0.024)$, daily consumption of milk and dairy products $(-0.188, P=0.017)$, going out twice or less a week $(-0.1605$; $P=0.027)$, status of self-rated health as 'poor' or 'neither good nor poor' $(-0.185 ; P=0.009)$, and need of nursing care $(-0.405 ; P=0.027)$. Prefectural average income showed a significant association with BMI (-0.846; $P=0.0021)$.

\section{Discussion}

Prefectural average income had a significant negative contextual association with individual-level BMI only for females. A previous study of inner city residents regarding barriers preventing access to healthy food reported that people living in low-income neighbourhoods have higher BMI (Furey, Strugnell, \& McIlveen, 2001). However, this is not applicable to our subjects. Our result that elderly females living in prefectures with high average incomes are lean might reflect the wish to have a slender body. While this is generally observed among the youth, it also applies to older adults in higher-income prefectures. This might lead to an increase in the number of frail elderly in higher-income prefectures.

Looking at the individual-level results for women's BMI, factors of age, need for nursing care, low subjective health, locomotive syndrome, a low frequency of outings, and dairy consumption were associated with a low BMI. While, living in a household with their child(ren) and consumption of meat, fish, and soy products were associated with a high BMI. Aging, living environment, illness, and mental wellness are typical factors that often contribute to a low BMI for older adults. A decrease in overall food, calorie, and protein intake resulting not only from a decrease in the sense of taste and smell, but also reduced masticatory ability, dysphagia, the deterioration of 
digestive organs, and a decrease in appetite due to illness or the side effects of medications are considered to contribute to a reduction of BMI with age.

Older women living with their children had higher BMIs than single and married women, and low subjective health was associated with a low BMI. We inferred that the reason for this is that when living and eating with their children, in addition to being able to supplement their nutrition with the same foods their children eat and improve their appetite, the mental wellness that comes from interacting with family improved their BMI. The BMI of females who went out twice or less a week was significantly lower than that of females who went out almost every day. A possible reason is that a decreased frequency of going out leads to a loss of muscle mass and, consequently, to muscle weakness, a condition known as sarcopenia (Ministry of Health, Labour and Welfare, 2015a), resulting in a decrease in BMI. The loss of going out leads to a weakening of social capital, which is an important factor in the prevention of noncommunicable diseases among the older population (Kondo, 2007). Our result supports the preventive approach of encouraging older people to go out. Nakamura et al. (2002) stated that the subjective health level of older adults can be improved and maintained by participating in social activities (Nakamura et al., 2002). It is essential to spread awareness that a decrease in outings, much like one-person households, leads to the weakening of social relationships and is implicated in life-style related illnesses (Kondo, 2007). This study supports a preventive approach by encouraging more outings for older adults.

In this study, older women who consumed foods high in protein such as meat, fish, eggs, and soy products daily had high BMI. Since there was a positive correlation between protein intake and calorie intake, we inferred that this result reflected an increase in the latter. It is reported that, in general, meal frequency decreases with age in both males and females (Kakuta, Okubo, \& Yamamoto, 1995). It is expected that the increase in the percentage of one-person elderly households may accelerate the number of elderly with low BMI. Older women in this study who consumed milk and dairy products daily also showed significantly lower BMIs. Previous reports have shown that for older women who consume milk daily, there is an increase in their bone strength and muscle mass (Uenishi, 2007). Though a low BMI is correlated with a greater chance of having osteoporosis, this cannot be verified by the results of the present study in which individuals who consume milk or dairy products had significantly low BMIs. As this was a cross-sectional study, with limited time, it may be that having a low BMI led to the consumption of milk and dairy products to prevent osteoporosis.

Males who encounter difficulty in chewing have lower BMI. Difficulty in chewing has a direct effect on digestion. It is also an indicator of individual-level socioeconomic status (Howard, Sungwoo, \& Amid, 2016). Individual-level income may reflect male BMI more clearly than female BMI. The 2010 National Health and Nutrition Survey in Japan (Ministry of Health, Labour and Welfare, 2013) yielded a controversial result regarding the individual-level effect: while there was no significant difference in the percentage of obese males between high and low-income individuals, the percentage of obese females was higher among low than high-income individuals. Research results on the effect of social disparity on health among older adults have accumulated and must be pursued in the context of the superaged status of society.

In this survey, more than $50 \%$ of males lived in married-couple households, whereas $32.8 \%$ of females lived in one-person households. The percentage of females who lived in one-person households increased with age because the average life expectancy of females ( 87.05 years) is longer than that of males (80.79 years) in Japan (Cabinet Office, Japan, 2015; Ministry of Health, Labour and Welfare, 2015b). The results indicate that the subjects were representative of the older population regarding familial background.

\subsection{Limitations of This Study}

This study is limited in that it is not suitable for risk assessment because it is cross-sectional and may include results from backward causation. Questionnaires are self-reported and responses might not be accurate. The subject group is also limited as the study did not make use of random sampling from a registry and there was a limited sample of men. In addition, since income is based on information at the prefectural level, ecological fallacies cannot be avoided. In the future, confirmation via a longitudinal survey using various indices will be needed to gain a better understanding of the factors that impact the BMI of older adults.

\section{Conclusion}

This nationwide questionnaire survey involving face-to-face interviews indicated that prefectural average income has a significant negative contextual association with individual-level BMI only for females; females with a low rate of going out have lower BMI; and females living with children have higher BMI. Social environment may be correlated with BMI in the older population. 


\section{Ethics Approval, Consent to Participate}

Since the subjects were asked about their households and personal affairs, we took all possible measures to protect and manage the subjects' personal data and to dispel fears regarding privacy. The interviewers obtained consent from subjects after fully explaining the purpose and methods of this study and that the participation in this survey was voluntary. The survey and analysis were conducted with the approval of the Ethics Committee of Tokiwa University (No. 100025).

\section{Consent for Publication}

Not applicable.

\section{Availability of Data and Materials}

The research datasets for this paper are unsuitable for public deposition due to ethical restrictions. However, the datasets used and/or analyzed in the present study are available from the corresponding author on reasonable request.

\section{Funding}

No funding supported this study.

\section{Authors' Contributions}

FO 1) designed the study, 2) coordinated and supervised the Survey on Dietary Environment in Relation to Difficulty in Shopping and Current Health Conditions of Household Elderly, 3) analyzed the data, 4) created the original research question, and 5) was a major contributor in writing the manuscript. ST completed the statistical analysis. All authors discussed, revised the manuscript, and approved the final version of the manuscript.

\section{Acknowledgements}

Not applicable.

\section{Competing Interests Statement}

The authors declare that they have no competing interests.

\section{References}

Berkman, L. F., \& Kawachi, I. (2000). Social epidemiology. Oxford University Press, Oxford New York.

Blakely, T. A., \& Kawachi, I. (2001). What is the difference between controlling for mean versus median income in analyses of income inequality? J Epidemiol Community Health, 55, 352-353. https://doi.org/10.1136/jech.55.5.352

Blaum, C. S., Xue, Q. L., Michelon, E., Semba, R. D., \& Fried, L. P. (2005). The association between obesity and the frailty syndrome in older women: the Women's Health and Aging Studies. J Am Geriatr Soc, 53, 927-934. https://doi.org/10.1111/j.1532-5415.2005.53300.x

Cabinet Office, Japan. (2011). Report on Prefectural Accounts for Fiscal 2011. National Accounts Division, Economic and Social Research Institute, Tokyo.

Cabinet Office, Japan. (2014). Annual Report on the Aging Society 2014, Tokyo, 19-23. [in Japanese]. Retrieved January 24 30, 2020, from http://www8.cao.go.jp/kourei/whitepaper/w-2014/zenbun/

Cabinet Office, Japan. (2015). Annual Report on the Aging Society. The Situation of Aging, Tokyo, 12-14.

Examination Committee of Criteria for "Obesity Disease" in Japan, Japan Society for Study of Obesity. (2011). Criteria for obesity disease in Japan 2011. J Jpn Soc Study Obesity, 17, 9-10. (supplement). https://doi.org/10.1253/circj.66.987

Fujino, Y., Tamakoshi, A., Iso, H., Inaba, Y., Kubo, T., Ide, R., ..., \& Yoshimura, T. (2005). JACC study group: A nationwide cohort study of educational background and major causes of death among the elderly population in Japan. Prev Med, 40, 444-451. https://doi.org/10.1016/j.ypmed.2004.07.002

Furey, S., Strugnell, C., \& Mcllveen, M. H. (2001). An investigation of the potential existence of "food deserts" in rural and urban areas of Northern Ireland. Agric Human Values, 18, 447-457. https://doi.org/10.1023/A:1015218502547

Fukuda, Y., \& Imai, H. (2007). Review of research on social inequalities in health in Japan. J Natl Inst Public Health, 56, 56-62.

Global BMI Mortality Collaboration. (2016). Body-mass index and all-cause mortality: 
individual-participant-data meta-analysis of 239 prospective studies in four continents. Lancet, 388, 776-786. https://doi.org/10.1016/S0140-6736(16)30175-1

Grabowski, D. C., \& Ellis, J. E. (2001). High body mass index does not predict mortality in older people: analysis of the Longitudinal Study of Aging. $J$ Am Geriatr Soc, 49, 968-979. https://doi.org/10.1046/j.1532-5415.2001.49189.x

Haass, M., Kitzman, D. W., Anand, I. S., Miller, A., Zile, M. R., Massie, B. M., \& Carson, P. E. (2011). Body mass index and adverse cardiovascular outcomes in heart failure patients with preserved ejection fraction: Results from the Irbesartan in Heart Failure with Preserved Ejection Fraction (I-PRESERVE) trial. Circ Heart Fail, 4, 324-331. https://doi.org/10.1161/CIRCHEARTFAILURE.110.959890

Howard, B., Sungwoo, L., \& Amid, I. (2016). The oral health of upper income Americans. J Public Health Dentistry, 76, 192-197. https://doi.org/10.1111/jphd.12135

Ichida, Y., Kondo, K., Hirai, H., Hanibuchi, T., Yoshikawa, G., \& Murata, C. (2009). Social capital, income inequality and self-rated health in Chita peninsula, Japan: a multilevel analysis of older people in 25 communities. Soc Sci Med, 69, 489-499. https://doi.org/10.1016/j.socscimed.2009.05.006

Imai, H. (2007). Social inequalities in health and economic disparities in Japan. [in Japanese]. $J$ Natl Inst Public Health, 56, 55.

Kakuta, K., Okubo, M., \& Yamamoto, M. (1995). Assessment of dietary habits in aged single person and evaluation of present community meal service for them. J Home Econ Jpn, 46, 959-968.

Kawachi, I., Fujisawa, Y., \& Takano, S. (2007). The Health of Japanese-What Can We Learn from America? [in Japanese]. J Natl Inst Public Health, 56, 114-117.

Kenchaiah, S., Pocock, S. J., Wang, D., Finn, P. V., Zornoff, L. A., Skali, H., ..., \& Solomon, S. D., CHARM Investigators. (2007). Body mass index and prognosis in patients with chronic heart failure: Insights from the Candesartan in heart failure: Assessment of reduction in mortality and morbidity (CHARM) program. Circulation, 116, 627-636. https://doi.org/10.1161/CIRCULATIONAHA.106.679779

Kondo, K. (2007). Exploring "Inequalities Health": A Large-Scale Social Epidemiological Survey for Care Prevention in Japan. Igaku Shoin, Tokyo.

Kondo, N., Kawachi, I., Hirai, H., Kondo, K., Subramanianm S.V., Hanibuchi, T., \& Yamagata, Z. (2009). Relative deprivation and incident functional disability among older Japanese women and men: prospective cohort study. J Epidemiol Community Health, 63, 461-467. https://doi.org/10.1136/jech.2008.078642

Kunimura, A., Ishii, H., Uetani, T., Aoki, T., Harada, K., Hirayama, K., ..., \& Murohara, T. (2017). Impact of Geriatric Nutritional Risk Index on cardiovascular outcomes in patients with stable coronary artery disease. $J$ Cardiol, 69, 383-388. https://doi.org/10.1016/j.jjcc.2016.09.004

Ministry of Health, Labour and Welfare. (2010). Summary of Results of Comprehensive Survey of Living Conditions 2010 (IV Situation of Long-Term Care), Tokyo. [in Japanese]. Retrieved January 24 30, 2020, from http://www.mhlw.go.jp/toukei/saikin/hw/k-tyosa/k-tyosa10/4-2.html

Ministry of Health, Labour and Welfare. (2011). Summary of National Health and Nutrition Survey in Japan 2011, Tokyo, 7-18.

Ministry of Health, Labour and Welfare. (2013). Summary of National Health and Nutrition Survey in Japan 2010, Tokyo, 171.

Ministry of Health, Labour and Welfare. (2015a). Dietary Reference Intakes for Japanese 2015. Tokyo, 376-377. $\begin{array}{lllll}\text { Retrieved } & \text { January } & 24 & 30, & 2020,\end{array}$ https://www.mhlw.go.jp/file/06-Seisakujouhou-10900000-Kenkoukyoku/Full_DRIs2015.pdf

Ministry of Health, Labour and Welfare. (2015b). Abridged Life Table, 2015. Retrieved January 24 30, 2020, from https://www.mhlw.go.jp/english/database/db-hw/lifetb15/index.html

Murata, C., Kondo, K., Hirai, H., Ichida, Y., \& Ojima, T. (2008). Association between depression and socio-economic status among community-dwelling elderly in Japan: the Aichi Gerontological Evaluation Study (AGES). Health Place, 14, 406-414. https://doi.org/10.1016/j.healthplace.2007.08.007

Nakamura, Y., Kaneko, I., Kawamura, Y., Sakano, T., Naito, K., Maeda K., ..., \& Hashimoto., S. (2002). Factors associated with self-rated health for non-institutionalized aged persons. [in Japanese]. Jpn J Pub Health, 49, 409-419. 
Okada, F., Hayakawa, F., Kugu, F., Yano, H., Toyama, M., Kitamura, H., \& Uetani, R. (2012). Survey on dietary environment in relation to difficulty in shopping and current health conditions of household elderly. [in Japanese]. Japanese Association of Dietary Life, Tokyo, 122-125.

Okada, F., Toyokawa, S., Kaneko, T., \& Furuhata, T. (2016). The adverse relationship of locomotive syndrome on access to social capital, life satisfaction, and self-rated health among retired household elderlies-survey on dietary environment in relation to difficulty in shopping and current health conditions of household elderly-. Jpn J Health Hum Ecol, 82, 171-181. https://doi.org/10.3861/jshhe.82.171

Okada, F., Toyokawa, S., Kaneko, T., \& Furuhata, T. (2020). Frequency of Going Out and Locomotive Syndrome Among Japanese Female Elderlies. Global J Health Sci, 12. https://oi.org/10.5539/gjhs.v12n1p80

Ota, A., Kondo, N., Murayama, N., Tanabe, N., Shobugawa, Y., \& Kondo, K., Japan Gerontological Evaluation Study (JAGES) group. (2016). Serum albumin levels and economic status in Japanese older adults. PLoS One. https://doi.org/10.1371/journal.pone.0155022

Sugiyama, M. (2005). Research on nutrition and food services management for the elderly 2004-For improvement of nutritional status of elderly in need of care [in Japanese]. Annual Report on Ministry of Health, Labor and Welfare-Funded Study, Tokyo, 377.

Takemi, Y., \& Koiwai, K. (2017). Strategy For prevention of undernutrition in the elderly: Meal delivery service and eating together in the community for health care and promotion. J Natl Inst Public Health, 66, 603-611.

Tamakoshi, A., Yatsuya, H., Lin, Y., Tamakoshi, K., Kondo, T., Suzuki, S., ..., \& Kikuchi, S. JACC Study Group. (2010). BMI and all-cause mortality among Japanese older adults: findings from the Japan Collaborative Cohort Study. Obesity, 18, 362-369. https://doi.org/10.1038/oby.2009.190

Uenishi, K. (2007) Consumption of milk and dairy products and health, especially on its relationship to life style related diseases [in Japanese]. Milk Science, 55, 277-286.

Wilkinson, R., \& Marmot, M. (2003). World Health Organization. Center for Urban Health: The solid facts. Social determinants of health. World Health Organization, Regional Office for Europe, Copenhagen, 7-29. 


\section{Appemdix}

Table 2. elationship of average income per capita in prefectures and individual-level factors with BMI of the elderly in multilevel analysis (males)

\begin{tabular}{|c|c|c|c|c|c|c|}
\hline & \multicolumn{3}{|c|}{ One independent variable } & \multicolumn{3}{|c|}{ Multilevel multivariable } \\
\hline & $\beta$ & $\mathrm{SE}$ & P-value & $\beta$ & $\mathrm{SE}$ & $P$-value \\
\hline \multicolumn{7}{|l|}{ INDIVIDUAL LEVEL } \\
\hline Age (years) & -0.059 & 0.008 & $<0.001^{\dagger}$ & -0.044 & 0.009 & $<0.001 \ddagger$ \\
\hline \multicolumn{7}{|l|}{ Household (ref: Living with children, and others) } \\
\hline One-person household & -0.576 & 0.173 & $0.001 \dagger$ & -0.086 & 0.279 & $0.756^{\ddagger}$ \\
\hline Married-couple household & -0.274 & 0.137 & $0.046 \dagger$ & 0.034 & 0.255 & $0.895^{\ddagger}$ \\
\hline \multicolumn{7}{|l|}{ Major source of income (ref: other than pension) } \\
\hline Pension & -0.155 & 0.072 & $0.031 \dagger$ & -0.317 & 0.237 & $0.181+$ \\
\hline \multicolumn{7}{|l|}{ Use of national $\mathrm{n}$ ursing-care i nsurance services } \\
\hline Support required & -1.135 & 0.264 & $<0.001^{\dagger}$ & -0.779 & 0.269 & $0.004+$ \\
\hline Need of nursing care & -1.195 & 0.266 & $<0.001^{\dagger}$ & -0.847 & 0.271 & $0.002 \div$ \\
\hline \multicolumn{7}{|l|}{ Self-rated health (ref: good and rathar good) } \\
\hline Poor, and neither good nor poor & 0.121 & 0.117 & $0.298 \dagger$ & -0.080 & 0.122 & $0.513+$ \\
\hline \multicolumn{7}{|l|}{ State of the tooth (ref: good) } \\
\hline It is hard to chew & -0.334 & 0.119 & $0.005 \dagger$ & -0.241 & 0.122 & $0.048+$ \\
\hline \multicolumn{7}{|l|}{ Diseases under treatment } \\
\hline Locomotive syndrome & -0.271 & 0.165 & $0.100 \dagger$ & -0.025 & 0.166 & $0.881^{\ddagger}$ \\
\hline \multicolumn{7}{|l|}{ Daily consumption } \\
\hline Meat, fish, eggs, and soy products & 0.216 & 0.265 & $0.414 \dagger$ & 0.181 & 0.268 & $0.500+$ \\
\hline Milk and dairy products & -0.189 & 0.124 & $0.127 \dagger$ & -0.157 & 0.125 & $0.225+$ \\
\hline \multicolumn{7}{|c|}{ Meal frequency per day (ref: More than three meals) } \\
\hline Two meals or less & 0.586 & 0.262 & $0.026 \dagger$ & 0.612 & 0.262 & $0.020 \div$ \\
\hline \multicolumn{7}{|c|}{ Frequency of going out (ref: More than three times a week) } \\
\hline It is as follows twice a week & -0.256 & 0.118 & $0.030 \dagger$ & -0.052 & 0.120 & $0.667^{\ddagger}$ \\
\hline \multicolumn{7}{|l|}{ PREFECTURAL LEVEL } \\
\hline Prefecture average income (1 thousand yen) & -0.317 & 0.272 & $0.101+$ & -0.312 & 0.258 & $0.227+$ \\
\hline
\end{tabular}

$\dagger:$ Fixed effect linear regression model.

†:Randome intercept linear regression model $\mathrm{N}=2199$. 
Table 3. Relationship of average income per capita in prefectures and individual-level factors with BMI of the elderly in multilevel analysis (females)

\begin{tabular}{|c|c|c|c|c|c|c|c|}
\hline & \multicolumn{3}{|c|}{ One independent variable } & & \multicolumn{3}{|c|}{ Multilevel multivariable } \\
\hline & $\beta$ & SE & P-value & & $\beta$ & SE & P-value \\
\hline \multicolumn{8}{|l|}{ INDIVIDUAL LEVEL } \\
\hline Age (years) & -0.048 & 0.005 & $<0.001 \dagger$ & -0.055 & 0.006 & $<0.001+$ & -0.048 \\
\hline \multicolumn{8}{|l|}{ Household (ref: Living with children, and others) } \\
\hline One-person household & -0.241 & 0.084 & $0.004 \dagger$ & -0.394 & 0.183 & $0.031+$ & -0.241 \\
\hline Married-couple household & -0.132 & 0.086 & $0.126 \dagger$ & -0.539 & 0.178 & $0.002+$ & -0.132 \\
\hline \multicolumn{8}{|l|}{ Major source of income (ref: other than pension) } \\
\hline Pension & -0.430 & 0.123 & $<0.001 \dagger$ & 0.262 & 0.169 & $0.122+$ & -0.430 \\
\hline \multicolumn{8}{|l|}{ Use of national $\mathrm{n}$ ursing-care i nsurance services } \\
\hline Support required & -0.110 & 0.132 & $0.406 \dagger$ & 0.163 & 0.138 & $0.237 \dagger$ & -0.110 \\
\hline Need of nursing care & -0.794 & 0.178 & $<0.001 \dagger$ & -0.405 & 0.183 & $0.027+$ & -0.794 \\
\hline \multicolumn{8}{|l|}{ Self-rated health (ref: good and rathar good) } \\
\hline Poor, and neither good nor poor & -0.143 & 0.068 & $0.036 \dagger$ & -0.185 & 0.071 & $0.009+$ & -0.143 \\
\hline \multicolumn{8}{|l|}{ State of the tooth (ref: good) } \\
\hline It is hard to chew & -0.087 & 0.070 & $0.219 \dagger$ & -0.051 & 0.072 & $0.482+$ & -0.087 \\
\hline \multicolumn{8}{|l|}{ Diseases under treatment } \\
\hline Locomotive syndrome & 0.283 & 0.077 & $<0.001 \dagger$ & 0.403 & 0.080 & $<0.001+$ & 0.283 \\
\hline Daily consumption & 0.494 & 0.188 & $0.009 \dagger$ & 0.430 & 0.190 & $0.024+$ & 0.494 \\
\hline Meat, fish, eggs, and soy products & -0.144 & 0.078 & $0.066 \dagger$ & -0.188 & 0.079 & $0.017 \ddagger$ & -0.144 \\
\hline Milk and dairy products & 0.212 & 0.181 & $0.242 \dagger$ & 0.291 & 0.180 & $0.106+$ & 0.212 \\
\hline \multicolumn{8}{|l|}{ Meal frequency per day (ref: More than three meals) } \\
\hline Two meals or less & -0.274 & 0.069 & $<0.001 \dagger$ & -0.160 & 0.072 & $0.027+$ & -0.274 \\
\hline $\begin{array}{l}\text { Frequency of going out (ref: More than three times a } \\
\text { week) }\end{array}$ & -0.804 & 0.256 & $<0.001 \ddagger$ & -0.846 & 0.129 & $0.001+$ & -0.804 \\
\hline It is as follows twice a week & -0.048 & 0.005 & $<0.001 \dagger$ & -0.055 & 0.006 & $<0.001+$ & -0.048 \\
\hline \multicolumn{8}{|l|}{ PREFECTURAL LEVEL } \\
\hline Prefecture average income (1 thousand yen) & -0.241 & 0.084 & $0.004 \dagger$ & -0.394 & 0.183 & $0.031 \dagger$ & -0.241 \\
\hline
\end{tabular}

$\dagger:$ Fixed effect linear regression model.

†:Randome intercept linear regression model $\mathrm{N}=2199$.

\section{Copyrights}

Copyright for this article is retained by the author(s), with first publication rights granted to the journal.

This is an open-access article distributed under the terms and conditions of the Creative Commons Attribution license (http://creativecommons.org/licenses/by/4.0/). 